\title{
Reemergence of Sexually Transmitted Antimicrobial Resistant Shigellosis in Men Who Have Sex with Men \\ Yuan-Ti Lee ${ }^{1,2,3^{*}}$, Shiuan-Chih Chen ${ }^{1,2,4}$ and Chi-Ho Chan ${ }^{1,2,5,6}$
}

${ }^{1}$ Institute of Medicine, Chung Shan Medical University, Taichung 40201, Taiwan

${ }^{2}$ School of Medicine, Chung Shan Medical University, Taichung 40201, Taiwan

${ }^{3}$ Division of Infectious Diseases, Department of Internal Medicine, Chung Shan Medical University Hospital, Taichung 40201, Taiwan

${ }^{4}$ Department of Family and Community Medicine, Chung Shan Medical University Hospital, Taichung 40201, Taiwan

${ }^{5}$ Department of Microbiology and Immunology, Chung Shan Medical University, Taichung 40201, Taiwan

${ }^{6}$ Institute of Microbiology and Immunology and School of Medicine, Chung Shan Medical University, Taichung, Taiwan

\begin{abstract}
Shigellosis is an acute gastrointestinal infection. Shigella has no reservoir in nature and the transmission of this disease is virtually always from one person to another. The normal routes of transmission for infectious gastrointestinal diseases are food contamination or/ and oral-fecal contact [1]. Since the 1970s, shigellosis has also been reported as a sexually transmitted infection (STI) in men who have sex with men (MSM) due to unprotected sexual activity [2]. Recently, epidemiological data has shown that MSM have tended to get the sexually transmitted form of these diseases at much higher rates than the general population [3].
\end{abstract}

A disease that was not transmitted sexually may become one that is. For example, a few years ago in countries such as the USA, England and Wales and Australia, shigellosis was found within the MSM community who were infected with HIV [4-7]. There is an ongoing Shigella flexneri (S. flexneri) serotype 3a prolonged MSM-associated outbreak in England and Wales which began in 2009 [7]. Shigellosis now appears to have become a worldwide problem [2]. We have recently seen data of communicable diseases from the Taiwan Centers for Disease Control and Prevention. The number of the cases related to the sexual transmission such as acute hepatitis A and $C$, Entamoeba hystolytica and shigellosis increased within the MSM community [8-13]. In Taiwan from 2005 to 2014, there was a low shigellosis incidence rate $(0.7 / 100,000$ persons) [8]. However, between June 2015 and May 2016, out of 200 shigellosis cases in northern and central Taiwan, there were $21 \mathrm{HIV}$ infected patients who domestically acquired infections of $S$. flexneri 3a. All 21 patients were men, 22-44 years of age, including 17 openly admitted MSM [13]. The concern is that what is now mainly limited to MSM infected with HIV, may spread to the general population and be transmitted through nonsexual means again.

Diarrhea is a common problem in individuals infected with HIV. It seems that a combination of antiretroviral therapy and certain behaviors have been changing the nature of infectious and noninfectious diarrhea in these individuals [14]. In a British study, certain behaviors were associated with the disease, such as having unprotected sex with a high number of partners, casual sex obtained through social media sites, and drug abuse (such as with crystal methamphetamine) which contributes to irresponsible sexual behavior $[15,16]$. Another factor is that HIV positive people are far more susceptible to the $S$. flexneri infection than others [17]. Taiwan has the same risk factors related to the disease and is following the same pattern as Britain, only a few years later $[6,18]$. What is happening in Taiwan now with the disease seems to have the same risk factors as in Britain, only happening a few years later.

A big concern now is that it will become increasingly difficult to treat Shigellosis due to antibiotic resistance $[19,20]$. Ciprofloxacin is the current drug of choice for treatment and it is becoming less and

\section{Publication History:}

Received: November 17, 2017

Accepted: December 28, 2017

Published: December 30, 2017

\section{Keywords:}

Shigellosis, Antimicrobial resistant, Sexually transmitted infection, HIV-infected

less effective over time $[1,20]$. Several previous reports stated that there is a worldwide spread of ciprofloxacin-resistant Shigella sonnei (S. sonnei) among HIV-infected MSM [13,21,22]. This was not the case in Asia. However, between March and May 2015, nine ciprofloxacinresistant S. sonnei infections occurred among HIV-infected MSM within Taiwan, unassociated with foreign travel [13]. On an ominous note, azithromycin resistant $S$. flexneri 3a strains have been found in Taiwan already, mostly in HIV-infected MSM $[2,18,23]$. They were already spreading in Europe, Australia and North America and it is probable they were brought to Taiwan due to sexual transmission during foreign travel $[2,23,24]$.

In conclusion, the reemergence of antimicrobial resistant Shigellosis as a sexually transmitted infection is a growing concern. It is primarily associated with HIV-positive MSM having unprotected sex with direct oral-anal contact. Chemsex drug use can compound the problem. Due to the fact that some patients are asymptomatic carriers, it is unlikely that doctors will test for Shigellosis. We suggest that, in addition to the other tests for sexually transmitted diseases normally performed on these patients, testing for Shigellosis should be added. This would be much easier if there were a more rapid test than culturing. Of especial concern is the rise of antimicrobial resistance internationally due mainly to sexual transmission. In high prevalence areas in South-east Asia, fluoroquinolone resistant Shigella species are not predominantly transmitted sexually [13]. However, in low prevalence areas, it is likely that resistant strains are being transmitted sexually.

\section{Competing Interests}

The authors declares that they have no competing interests.

"Corresponding Author: Dr. Yuan-Ti Lee, Institute of Medicine, Chung Shan Medical University, \#110, Section 1, Jianguo N. Road, Taichung 40201, Taiwan, E-mail: leey521@gmail.com

Citation: Lee YT, Chen SC, Chan CH (2017) Reemergence of Sexually Transmitted Antimicrobial Resistant Shigellosis in Men Who Have Sex with Men. Int J Clin Med Microbiol 2: 126. doi: https://doi.org/10.15344/2456-4028/2017/126

Copyright: @ 2017 Lee et al. This is an open-access article distributed under the terms of the Creative Commons Attribution License, which permits unrestricted use, distribution, and reproduction in any medium, provided the original author and source are credited. 
Citation: Lee YT, Chen SC, Chan CH (2017) Reemergence of Sexually Transmitted Antimicrobial Resistant Shigellosis in Men Who Have Sex with Men. Int J Clin Med Microbiol 2: 126. doi: https://doi.org/10.15344/2456-4028/2017/126

Page 2 of 2

\section{References}

1. Musher DM, Musher BL (2004) Contagious Acute Gastrointestinal Infections. N Engl J Med 351: 2417-2427.

2. Baker KS, Dallman TJ, Ashton PM, Day M, Hughes G, et al. (2015) Intercontinental dissemination of azithromycin-resistant shigellosis through sexual transmission: a cross-sectional study. Lancet Infect Dis 15: 913-921.

3. Mohammed H, Mitchell H, Sile B, Duffell S, Nardone A, et al. (2016) Increase in Sexually Transmitted Infections among Men Who Have Sex with Men, England, 2014. Emerg Infect Dis 22: 88.

4. Baer JT, Vugia DJ, Reingold AL, Aragon T, Angulo FJ, et al. (1999) HIV infection as a risk factor for shigellosis. Emerg Infect Dis 5: 820-823.

5. O'Sullivan B, Delpech V, Pontivivo G, Karagiannis T, Marriott D, et al. (2002) Shigellosis Linked to Sex Venues, Australia. Emerg Infect Dis 8: 862-864.

6. Okame M, Adachi E, Sato H, Shimizu S, Kikuchi T, et al. (2012) Shigella sonnei Outbreak among Men Who Have Sex with Men in Tokyo. Japanese Journal of Infectious Diseases 65: 277-278.

7. Borg ML, Modi A, Tostmann A, Gobin M, Cartwright J, et al. (2012) Ongoing outbreak of Shigella flexneri serotype 3a in men who have sex with men in England and Wales, data from 2009-2011. Euro Surveill 17: 20137.

8. Taiwan Centers for Disease Control, Taiwan National Infectious Disease Statistics System.

9. Chen GJ, Lin KY, Hung CC, Chang SC (2017) Hepatitis A Outbreak Among Men Who Have Sex With Men in a Country of Low Endemicity of Hepatitis A Infection. J Infect Dis 215: 1339-1340.

10. Lee YL, Lin KY, Cheng CY, Li CW, Yang CJ (2017) Evolution of hepatitis A virus seroprevalence among HIV-positive adults in Taiwan. PLOS ONE 12: e0186338.

11. Lo YC, Tsai MS, Sun HY, Hung CC, Chuang JH, et al. (2015) National Trend and Characteristics of Acute Hepatitis C among HIV-Infected Individuals: A Matched Case-Control Study-Taiwan, 2001-2014. PLOS ONE 10: e0139687.

12. Lo YC, Ji DD, Hung CC (2014) Prevalent and Incident HIV Diagnoses among Entamoeba histolytica-Infected Adult Males: A Changing Epidemiology Associated with Sexual Transmission-Taiwan, 2006-2013. PLOS Negl Trop Dis 8: e3222.

13. Chiou CS, Izumiya H, Kawamura M, Liao YS, Su YS, et al.: (2016) The worldwide spread of ciprofloxacin-resistant Shigella sonnei among HIVinfected men who have sex with men, Taiwan. Clinical Microbiology and Infection 22: 383.e311-383.e316.

14. Logan C, Beadsworth MB, Beeching NJ (2016) HIV and diarrhoea: what is new? Curr Opin Infect Dis 29: 486-494.

15. Gilbart VL, Simms I, Jenkins C, Furegato M, Gobin M, et al. (2015) Sex, drugs and smart phone applications: findings from semistructured interviews with men who have sex with men diagnosed with Shigella flexneri $3 a$ in England and Wales. Sex Transm Infect 91: 598-602.

16. Kirby $\mathrm{T}$, Thornber-Dunwell $\mathrm{M}$ (2013) High-risk drug practices tighten grip on London gay scene. Lancet 381:101-102.

17. Daskalakis DC, Blaser MJ (2007) Another Perfect Storm: Shigella Men Who Have Sex with Men, and HIV. Clin Infect Dis 44: 335-337.

18. Liao YS, Liu YY, Lo YC, Chiou CS (2017) Azithromycin-Nonsusceptible Shigella flexneri 3a in Men Who Have Sex with Men, Taiwan, 2015-2016. Emerg Infect Dis 23: 345-346.

19. Replogle ML, Fleming DW, Cieslak PR (2000) Emergence of AntimicrobialResistant Shigellosis in Oregon. Clin Infect Dis 30: 515-519.

20. World Health Organization (2014) Antimicrobial resistance: global report on surveillance. World Health Organization.

21. Gaudreau C, Ratnayake R, Pilon PA, Gagnon S, Roger M, et al.: (2011) Ciprofloxacin-Resistant Shigella sonnei among Men Who Have Sex with Men, Canada, 2010. Emerg Infect Dis 17: 1747.

22. Hoffmann C, Sahly H, Jessen A, Ingiliz P, Stellbrink HJ, et al. (2013) High rates of quinolone-resistant strains of Shigella sonnei in HIV-infected MSM. Infection 41: 999-1003.
23. Gaudreau C, Barkati S, Leduc JM, Pilon PA, Favreau J, et al. (2014) Shigella spp. with Reduced Azithromycin Susceptibility, Quebec, Canada, 2012-2013. Emerg Infect Dis 20: 854.

24. Agaisse $H$ (2015) Shigella flexneri serotype 3a: the rise of a superbug. Lancet Infect Dis15: 867-868. 